\title{
A risk-return based model to measure the performance of portfolio management
}

\author{
Hamid Reza Vakili Fard ${ }^{a}$, Mahmood Ansar ${ }^{b^{*}}$ and Amir Yekezare ${ }^{b}$
}

\begin{abstract}
${ }^{a}$ Associate Prof, Department of Financial Management, Science and Research Branch, Islamic Azad University (IAU), Tehran, Iran ${ }^{b}$ Ph.D. Student, Department of Financial Management, Science and Research branch, Islamic Azad University (IAU), Tehran, Iran CHRON I C LE ABSTRACT

Article history:

Received May 4, 2014

Accepted 24 September 2014

Available online

September 292014

Portfolio optimization

Portfolio management

performance

KA Model

The primary concern in all portfolio management systems is to find a good tradeoff between risk and expected return and a good balance between accepted risk and actual return indicates the performance of a particular portfolio. This paper develops "A-Y Model" to measure the performance of a portfolio and analyze it during the bull and the bear market. This paper considers the daily information of one year before and one year after Iran's 2013 precedential election. The proposed model of this paper provides lost profit and unrealized loss to measure the portfolio performance. The proposed study first ranks the resulted data and then uses some non-parametric methods to see whether there is any change because of the changes in markets on the performance of the portfolio. The results indicate that despite increasing profitable opportunities in bull market, the performance of the portfolio did not match the target risk. As a result, using A-Y Model as a risk and return base model to measure portfolio management's performance appears to reduce risks and increases return of portfolio.
\end{abstract}

(C) 2014 Growing Science Ltd. All rights reserved.

\section{Introduction}

Capital markets as a crucial part of financial system play essential role in economic development (Markowitz, 1952, 1968). Most popular financial institutions such as mutual funds, hedge funds and exchange-traded funds help investors make appropriate financial decisions (Zhou \& Yin, 2003; Briec et al., 2004). Investment in such institutions may increase the diversification of investors' portfolio and decrease their risks. However, the most important issue is to select the best investment opportunity based on the performance of institutions. On the other hand, management of such institutions needs to evaluate the performance of their portfolio management. In the recognition that investment management is an on-going process, the performance of actively-managed portfolios needs to be monitored and evaluated to ensure that funds under management are efficiently invested in order to satisfy the mandate specified in the policy statement (Hsieh \& Hodnett, 2013). Therefore, evaluating portfolio performance has become an essential topic for the portfolio managers, investors and almost all of players in the financial markets. Portfolio performance evaluation serves two issues: the determination of whether investment objectives are met and the degree to which these objectives are, or are not surpassed.

*Corresponding author. Tel: +98-912-3571103

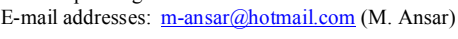

(c) 2014 Growing Science Ltd. All rights reserved. doi: $10.5267 /$ j.ms 1.2014.9.019 
While the objectives are hopefully the same for all parties associated with the management of portfolio, the desired information is not always identical. The investor is interested in the performance of a portfolio in the broader context of all investor assets. A manager, on the other hand, is concerned with a narrow set of objectives dictated by the investor (Singer, 1996). The question of how to evaluate the performance of a fund is far from being academic. Many funds with outstanding profits during their life have collapsed, and investors are more and more interested in the other dimensions of fund performance such as risk (Jagric et al., 2007). In a reward-risk framework, the investors either maximize the reward for a fixed risk or minimize the risk for a fixed reward. Moreover, the investors optimize their performance several times maximizing the reward for unity of risk and this strategy still yields an efficient portfolio in terms of reward and risk called a market portfolio (Stoyanov et al., 2007). Sharpe's Index (Sharpe, 1964, 1998) incorporates information determined by the return/ risk of the portfolio or other investment that is evaluated. Sharpe's performance measurement considers the total risk of the portfolio. Sharpe's performance model is normally stated as a risk premium/total risk. This shows the demanded additional return over investors' risk free interest rate when compared the total risk of the portfolio (Türegün \& Kaya, 2014). This paper develops a reward-risk based performance model and examines the implementation of the proposed model using some real market data.

One of the most important factors in measuring the performance of any portfolio is associated with weighting of individual securities within the portfolio (Sadjadi et al., 2011). The weight that a portfolio manager assigns to a given security in a portfolio can make a contribution to return that is just as important as the security selection and investment timing decisions (Block \& French, 2002). It is now well established that the construction of optimal hedge fund portfolios requires techniques that reach well beyond traditional mean variance analysis (Lamm, 2003). If mutual fund managers are interested in equal weighting, then the relevance of using a value-weighted index such as the S\&P 500 as a performance benchmark might be suboptimal. Just how much mutual fund managers actually slant their portfolios towards equal or value weighting is a question to be answered empirically (Block \& French, 2002). Current convictions are that different investment styles perform at various stages of the market cycle. Specifically, active manager's claim that performance is better in bear markets rather than in bull markets. During the bull market, majority of the value managers underweighted the technology sectors and subsequently underperformed the market. Cycling into the bear market, those very same value managers significantly outperformed. Hence, assuming market efficiency does not hold and that mutual funds can outperform the market, questioning at which points in the market cycle they outperform is logical with such recent situations as mentioned above (Hamidani, 2004). Qamruzzaman (2014) evaluated the performance of 32 growth-oriented mutual funds on the basis of monthly returns compared with benchmark returns. He used various risk adjusted performance measures and reported that, over the research period selected mutual funds indicated positive monthly return and upward trend compared with market return. Various risk return measures indicate similar performance indication with exception of few mutual funds scheme due to market return in inconsistent with return from mutual funds i.e., negative market return. It can be concluded that, the growth-oriented mutual funds have not performed better than their respect to volatility most of the funds have not performed better. Growth oriented mutual funds are expected to offer the advantages of diversification, market timing and selectivity. For broadening the depth of the capital market, it is necessary to float more mutual funds since these are good tools of mobilizing savings and providing investment opportunities to small savers. Wu (2014) examined the interaction between mutual fund performance and portfolio turnover and reported that active trading could influence on fund performance, but underperforming funds could also be traded actively to perform well. Petronio et al. (2014) discuss the portfolio selection problem using performance measures and introduce a new performance measure consistent with the choices of non-satiable risk-averse investors. In this paper, we introduce a portfolio performance model and evaluate the efficiency of model in bear and bull market. 


\section{The proposed study}

Khodaei Valahzaghard and Ansar (2013) developed Khodaei-Ansar (KA) Model to measure the performance of foreign currency portfolio management. For the proposed model of this paper, we develop K-A Model and propose a new Ansar-Yekezare (AY) model to meet stock market restrictions. A-Y Model allocates stocks to portfolios to optimize them in a reward-risk framework. The following notation summarizes details of our survey,

The proposed model of this paper uses the following model to measure lost Profit that presents the difference between performance of selected portfolio and best possible performance,

$\min \frac{\sqrt{\sum_{i=1}^{n} \sum_{j=1}^{n}\left(\omega_{i} \times \omega_{j} \times \delta_{i j}\right)}}{\sum_{i=1}^{n} \omega_{i} \times r_{i}}$

subject to

$\sum_{i=1}^{n} \omega_{i} \times r_{i}>0$
$\sum_{i j}=1$

where $\delta_{i j}$ is the variance between two firms, $\omega_{i}$ and $\omega_{j}$ are weights of firm $i$ and firms $j$, respectively. In addition, $r_{i}$ is the return of firm $i$. The proposed model of this paper uses the following to measure unrealized loss that presents the difference between performance of selected portfolio and the worst possible performance,

A-Y Statistics $= \begin{cases}\frac{\text { risk }}{\text { return - risk }} & \text { return }>\text { risk } \\ \frac{-1}{\text { risk } /(\text { return-risk })} & \text { return } \leq \text { risk }\end{cases}$

Therefore, we solve the following optimization problem,

$$
\max A-Y=\left\{\begin{array}{lc}
\frac{\sqrt{\sum_{i=1}^{n} \sum_{j=1}^{n}\left(w_{i} w_{j} \delta_{i j}\right)}}{\sum_{i=1}^{n} w_{i} r_{i}-\sqrt{\sum_{i=1}^{n} \sum_{j=1}^{n}\left(w_{i} w_{j} \delta_{i j}\right)}} & \text { if } \sqrt{\sum_{i=1}^{n} \sum_{j=1}^{n}\left(w_{i} w_{j} \delta_{i j}\right)}<\sum_{i=1}^{n} w_{i} r_{i} \\
-1 / \frac{\sqrt{\sum_{i=1}^{n} \sum_{j=1}^{n}\left(w_{i} w_{j} \delta_{i j}\right)}}{\sum_{i=1}^{n} w_{i} r_{i}-\sqrt{\sum_{i=1}^{n} \sum_{j=1}^{n}\left(w_{i} w_{j} \delta_{i j}\right)}} & \text { otherwise }
\end{array}\right.
$$

subject to

$\sum \omega_{i j}=1$

The performance of the portfolio management is determined as follows,

Portfolio management performance $=\frac{\text { Unrealized loss }}{\text { Unrealized loss }+ \text { lost profit }}$ 


\section{The results}

We have applied the proposed model of this paper on data collected from Tehran Stock Exchange. We compare results before and after recent presidential election in order to have better understanding on A-Y Model's process. Fig. 1 shows the summary of risk for optimal portfolio, selected portfolio and negative optimal portfolio. In addition, Fig. 2, demonstrates the return for optimal, selected and negative optimal portfolios. As we can observe from the results of Fig. 2, investment opportunities have been increased after the presidential election. The implementation of the Kolmogorov-Smirnov test on our data has indicated that most observations were not normally distributed and we, therefore, use Wilcoxon (Wilcoxon, 1945) and Mann-Whitney tests (Mann \& Whitney, 1947) to examine the performance of the proposed study.

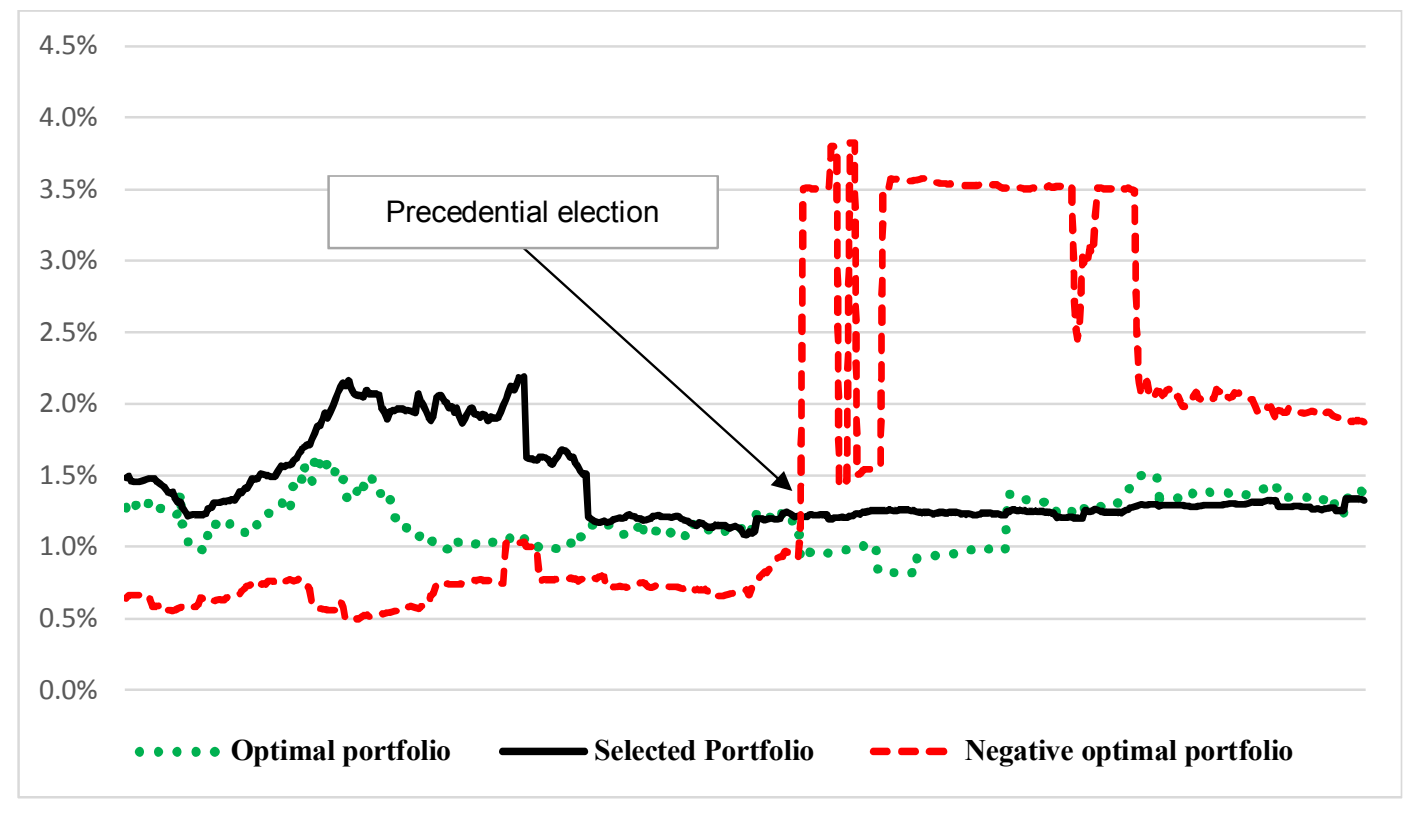

Fig. 1. The risk measure for optimal, selected and negative optimal portfolios

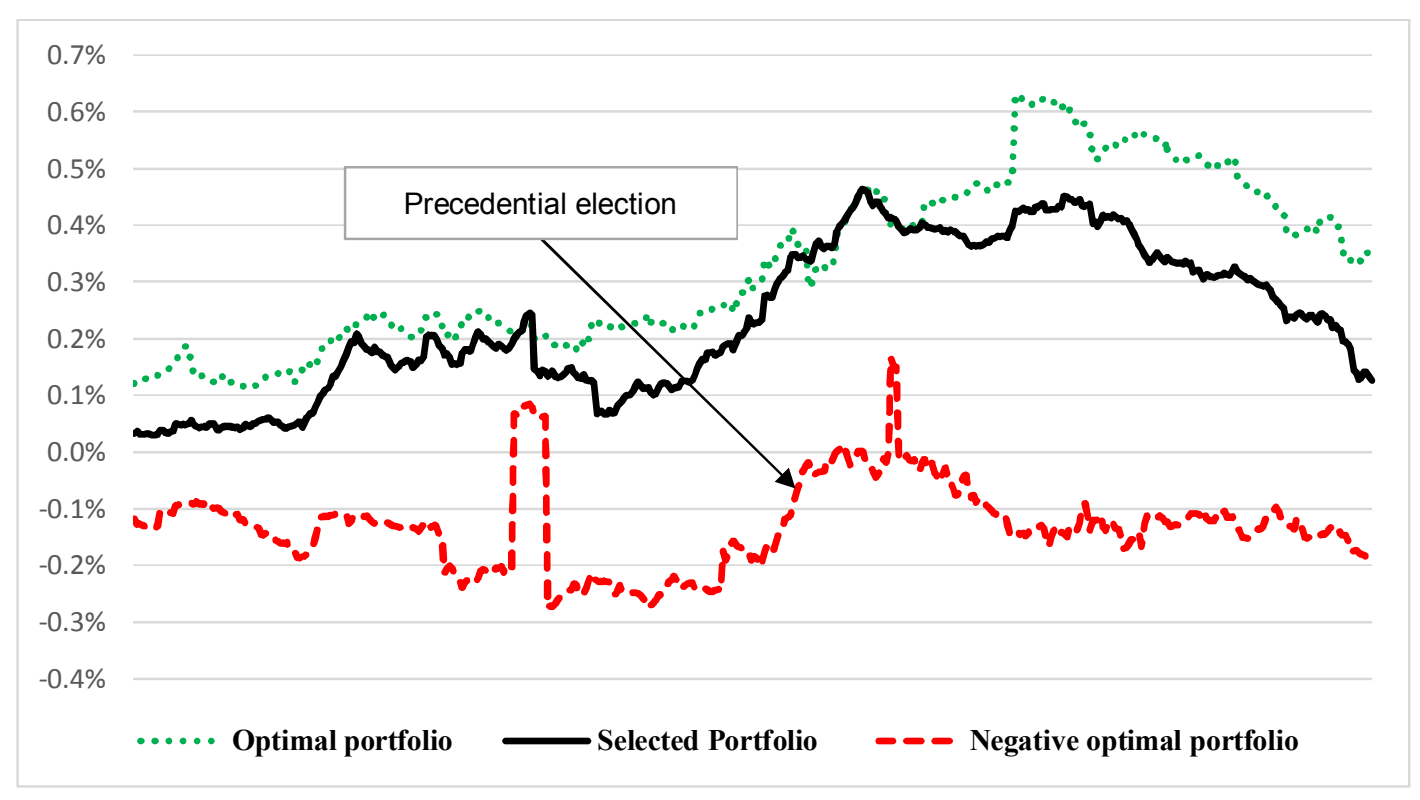

Fig. 2. The return measure for optimal, selected and negative optimal portfolios 
In order to have better understanding on unrealized loss and lost profit, we compare actual and predicted performance. Fig. 3 summarizes the results of our findings on unrealized loss. As we can observe, actual unrealized loss represented more volatile data than the predicted ones. Fig. 4 demonstrates the trend of actual and predicted loss profit. As we can observe from the results of Fig. 3 and 4, actual unrealized loss and lost profit are more volatile than the predicted ones. We have compared the mean of predicted versus actual performance using Mann-Whitney test and Table 1 demonstrates the results of our findings.

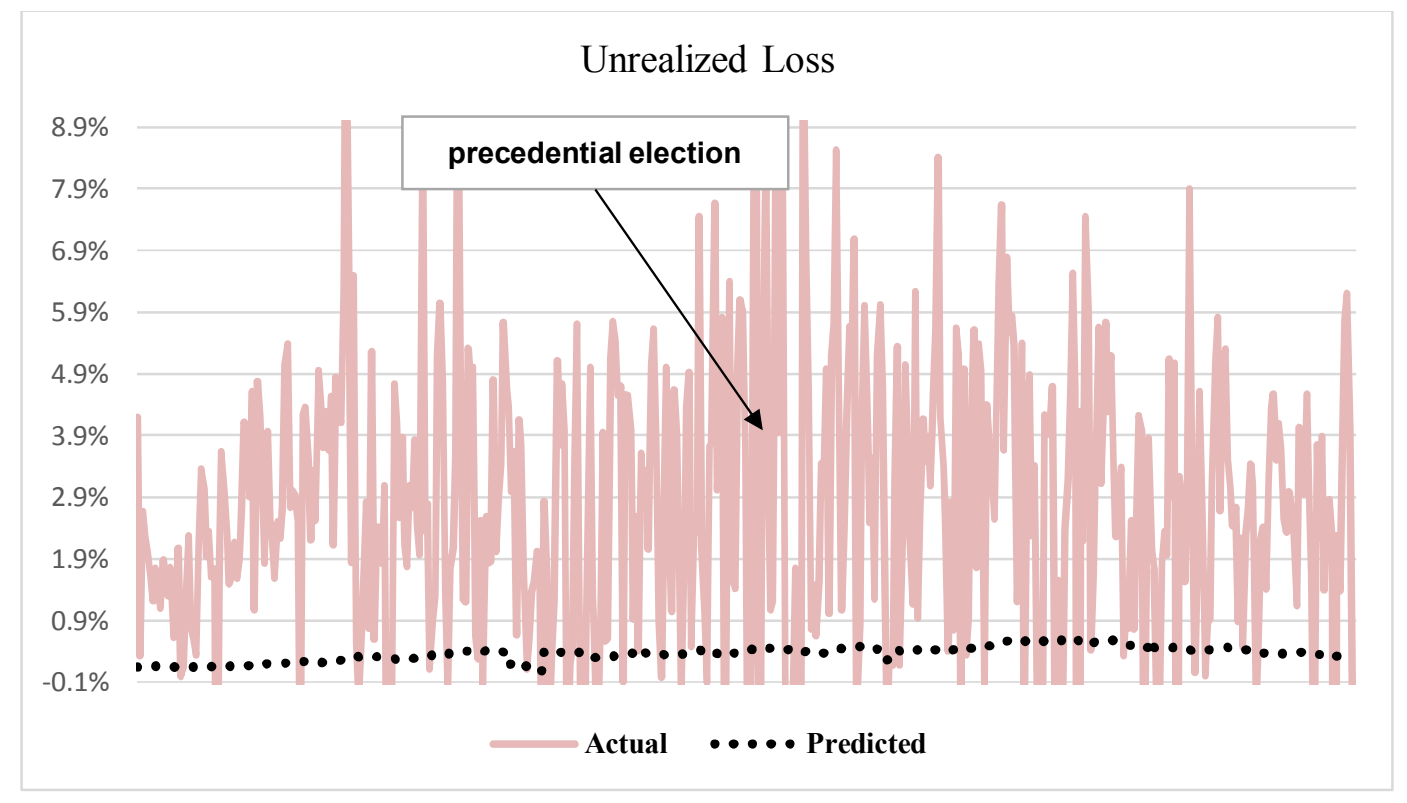

Fig. 3. Unrealized loss, predicted versus actual

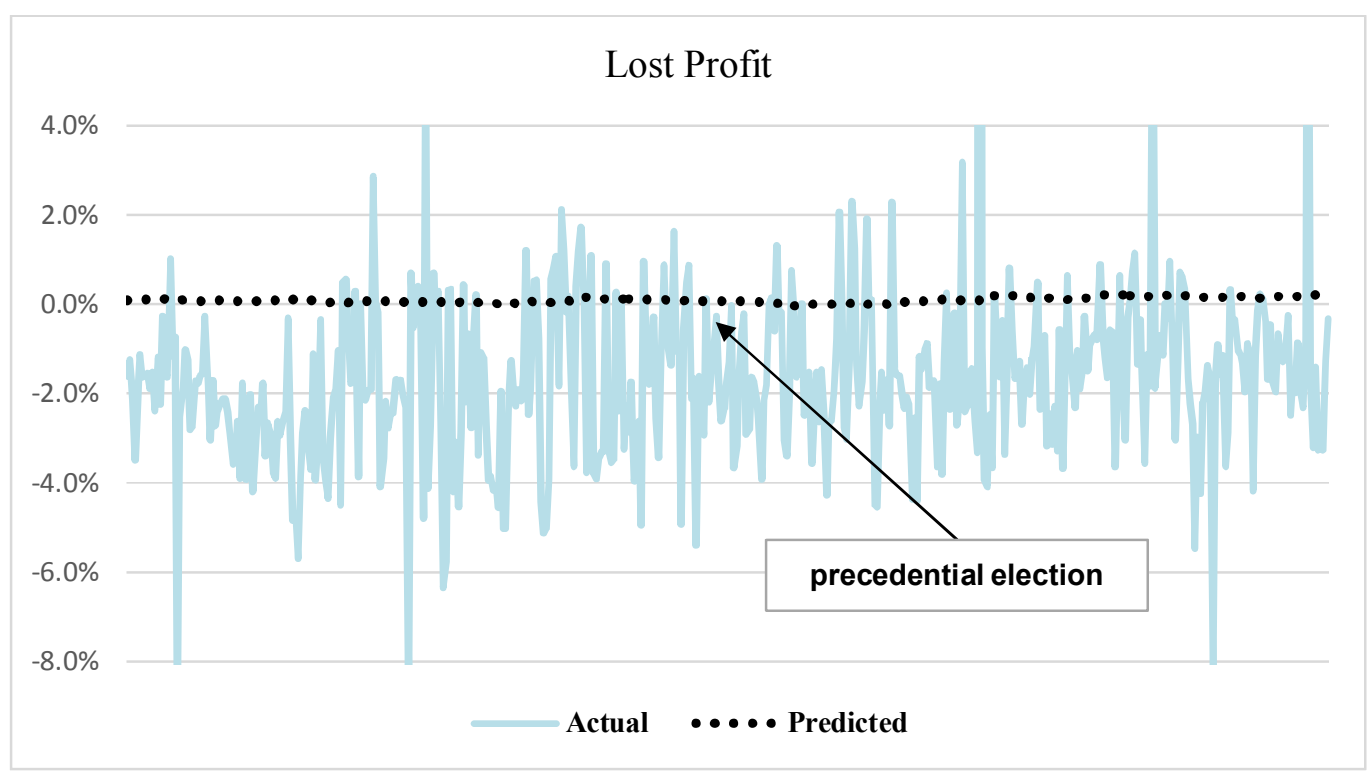

Fig. 4. The trend of actual and predicted loss profit 
Table 1

The summary of Mann-Whitney test on difference between actual and predicted information

\begin{tabular}{lccccc}
\hline & Period & $\mathrm{N}$ & $\mathrm{Z}$ & Sig. & Result \\
\hline Coefficient of Variation & Before election & 240 & -2.80 & 0.005 & Confirmed \\
& After election & 240 & & & \\
\hline A-Y statistics & Before election & 240 & -6.17 & 0.000 & Confirmed \\
& After election & 240 & & & \\
\hline
\end{tabular}

As we can observe from the results of Table 1, the null hypotheses in two cases are rejected when the level of significance is one percent that shows there is some difference between investment opportunities before and after presidential election in bear and bull market. Table 2 shows the results of Wilcoxon test before and after the presidential event.

As we can observe from the results of Table 2, in most cases, Wilcoxon test has rejected the null hypothesis and we can confirm that there was a difference between the data before and after presidential election. In addition, after presidential election, actual return has increased and coefficient of variation has been decreased. Now, we are able to examine the effects of portfolio management performance before and after presidential election using Mann-Whitney test. Table 3 presents the results of comparing the mean ranks for predicted performance measured by A-Y method. According to the results of Table 3, there is a meaningful difference between mean ranks of the predicted performance before and after presidential election. Similarly, Table 4 presents the results of comparing mean ranks for the actual performance measured by A-Y method.

Table 2

The summary of Wilcoxon test

\begin{tabular}{|c|c|c|c|c|c|c|c|c|}
\hline & & & & $\mathrm{N}$ & Mean rank & $\mathrm{Z}$ & Sig. & Result \\
\hline \multirow{8}{*}{ Return } & \multirow{4}{*}{ Unrealized loss } & \multirow{2}{*}{ Before election } & Predicted & 240 & 129 & & & \\
\hline & & & Actual & 240 & 54 & -12.1 & 0.000 & Confirmed \\
\hline & & \multirow{2}{*}{ After election } & Predicted & 240 & 132 & & & \\
\hline & & & Actual & 240 & 163 & -11.1 & 0.000 & Confirmed \\
\hline & \multirow{4}{*}{ Lost profit } & \multirow{2}{*}{ Before election } & Predicted & 240 & 45 & & & \\
\hline & & & Actual & 240 & 133 & -12.00 & 0.000 & Confirmed \\
\hline & & \multirow{2}{*}{ After election } & Predicted & 240 & 72 & & & \\
\hline & & & Actual & 240 & 127 & -11.4 & 0.000 & Confirmed \\
\hline \multirow{8}{*}{$\begin{array}{l}\text { Coefficient } \\
\text { of Variation }\end{array}$} & \multirow{4}{*}{ Unrealized loss } & \multirow{2}{*}{ Before election } & Predicted & 240 & 66 & & & \\
\hline & & & Actual & 240 & 125 & -12.3 & 0.000 & Confirmed \\
\hline & & \multirow{2}{*}{ After election } & Predicted & 240 & 141 & & & \\
\hline & & & Actual & 240 & 119 & -11.5 & 0.000 & Confirmed \\
\hline & \multirow{4}{*}{ Lost profit } & \multirow{2}{*}{ Before election } & Predicted & 240 & 126 & & & \\
\hline & & & Actual & 240 & 79 & -11.3 & 0.000 & Confirmed \\
\hline & & \multirow{2}{*}{ After election } & Predicted & 240 & 126 & & & \\
\hline & & & Actual & 240 & 115 & -1.2 & 0.245 & Not Confirmed \\
\hline
\end{tabular}

Table 3

The summary of mean ranks for predicted A-Y model

\begin{tabular}{cccccc}
\hline Period & $\mathrm{N}$ & Mean rank & $\mathrm{z}$ & Sig. & Result \\
\hline Before presidential election & 240 & 134.5 & -16.9 & 0.000 & Confirmed \\
After presidential election & 240 & 346.5 & & & \\
\hline
\end{tabular}

Table 4

The summary of mean ranks for actual A-Y model

\begin{tabular}{cccccc}
\hline Period & $\mathrm{N}$ & Mean rank & $\mathrm{z}$ & Sig. & Result \\
\hline Before presidential election & 240 & 230.6 & -1.57 & 0.118 & Not Confirmed \\
After presidential election & 240 & 250.4 & & & \\
\hline
\end{tabular}


According to the results of Table 4, there is not any meaningful difference between mean ranks of the actual performance before and after presidential election. Therefore, we reach a conclusion that presidential election had no impact on risk-reward portfolio management performance.

\section{Conclusion}

This paper has presented a new method to measure the performance of a portfolio and analyzed it during the bull and the bear market. The study considered the daily information of one year before and one year after Iran's 2013 precedential election. The proposed model of this paper provided lost profit and unrealized loss to measure the portfolio performance. The proposed study first ranked the resulted data and then applied some non-parametric methods to see whether there was any change because of the changes in markets on the performance of the portfolio. The results have indicated that despite increasing profitable opportunities in bull market, the performance of the portfolio did not match the target risk. As a result, using the proposed A-Y Model as a risk and return base model to measure portfolio management's performance has appeared to reduce risks and increases return of portfolio.

\section{Acknowledgement}

The authors would like to thank the anonymous referees for constructive comments on earlier version of this paper.

\section{References}

Block, S. B., \& French, D. W. (2002). The effect of portfolio weighting on investment performance evaluation: the case of actively managed mutual funds. Journal of Economics and Finance, 26(1), 16-30.

Briec, W., Kerstens, K., \& Lesourd, J. B. (2004). Single-period Markowitz portfolio selection, performance gauging, and duality: A variation on the Luenberger shortage function. Journal of Optimization Theory and Applications, 120(1), 1-27.

Hsieh, H., \& Hodnett, K. (2013). A review of performance evaluation measures for actively-managed portfolios. Journal of Economics and Behavioral Studies, 5(12), 815-824.

Hamidani, F. (2004). Mutual Fund Performance in Bull and Bear Markets: An Empirical Examination (Doctoral dissertation, Faculty of Business Administration-Simon Fraser University).

Jagric, T., Podobnik, B., Strasek, S., \& Jagric, V. (2007). Risk-adjusted performance of mutual funds: some tests. South-Eastern Europe Journal of Economics, 2, 233-44.

Khodaei Valahzaghard, M., \& Ansar, M. (2013). How banking sanctions influence on performance of foreign currency portfolio management. Management Science Letters, 3(2), 527-532.

Lamm Jr, R. M. (2003). Asymmetric returns and optimal hedge fund portfolios. The Journal of Alternative Investments, 6(2), 9-21.

Mann, H. B., \& Whitney, D. R. (1947). On a test of whether one of two random variables is stochastically larger than the other. The Annals of Mathematical Statistics, 18(1), 50-60.

Markowitz, H. (1952). Portfolio selection. The Journal of Finance, 7(1), 77-91.

Markowitz, H. M. (1968). Portfolio selection: efficient diversification of investments (Vol. 16). Yale university press.

Petronio, F., Lando, T., Biglova, A., \& Ortobelli, S. (2014). Optimal portfolio performance with exchange-traded funds, 17, 6-12.

Qamruzzaman, M. (2014). Comparative study on performance evaluation of mutual fund schemes in Bangladesh: An analysis of monthly returns. Journal of Business Studies Quarterly, 5(4), 190-209.

Sadjadi, S. J., Seyedhosseini, S. M., \& Hassanlou, K. (2011). Fuzzy multi period portfolio selection with different rates for borrowing and lending. Applied Soft Computing, 11(4), 3821-3826. 
Sharpe, W. F. (1964). Capital asset prices: A theory of market equilibrium under conditions of risk. The Journal of Finance, 19(3), 425-442.

Sharpe, W. F. (1998). The sharpe ratio. Streetwise-the Best of the Journal of Portfolio Management, 169-185.

Singer, B. (1996). Evaluation of portfolio performance: Aggregate return and risk Analysis. The Journal of Performance Measurement, 6-16.

Stoyanov, S. V., Rachev, S. T., \& Fabozzi, F. J. (2007). Optimal financial portfolios. Applied Mathematical Finance, 14(5), 401-436.

Türegün, N., \& Kaya, C. (2014). Performance evaluation of Turkish pension mutual funds. International Journal of Economics, Finance and Management, 3(1).

Wilcoxon, F. (1945). Individual comparisons by ranking methods. Biometrics bulletin, 1(6), 80-83.

$\mathrm{Wu}$, S.S. (2014). Interaction between mutual fund performance and portfolio turnover. Journal of Emerging Issues in Economics, Finance and Banking, 3(4).

Zhou, X. Y., \& Yin, G. (2003). Markowitz's mean-variance portfolio selection with regime switching: A continuous-time model. SIAM Journal on Control and Optimization, 42(4), 1466-1482. 